\title{
Promoting conceptual change through active learning using open source software for physics simulations
}

\author{
Mustafa Baser \\ Abant Izzet Baysal University, Turkey \\ This paper reports upon an active learning approach that promotes \\ conceptual change when studying direct current electricity circuits, using \\ free open source software, Qucs. The study involved a total of 102 \\ prospective mathematics teacher students. Prior to instruction, students' \\ understanding of direct current electricity was determined by a subset of a \\ previously developed multiple choice conceptual test. All students received \\ an active learning instruction using Qucs simulations. After instruction, the \\ same test was administered to the students to determine the effectiveness of \\ the instruction they received. Paired t-test analyses showed that students' \\ progress on understanding of direct current electricity was significant. A six \\ week delayed post-test revealed that this observed improvement promised \\ to be durable, at least in the short term. Students' evaluation of using Qucs is \\ also reported.
}

\section{Introduction}

Although physics researchers frequently use free open source software in their research and preparing their research reports (e.g., Octave, Gnuplot, $\mathrm{LaTeX}$ ), articles describing how to use open source as a teaching resource are relatively rare. Free and open source software (F/OSS or FOSS) is software which is liberally licensed to grant the right of users to study, change, and improve its design through the availability of its source code (for example see http://en.wikipedia.org/wiki/FOSS). Qucs is FOSS for simulating complicated analog electric circuits. Although Qucs is not designed for teaching simple electric circuits, this paper provides evidence that it can be used by physics educators to build active learning environments for teaching simple electric circuits.

Physics educators know that students come to physics classes with a range of misconceptions (Novak, 2002). Passive learning environments in traditional instruction do not help students to attain conceptual change 
(e.g. Eryilmaz, 2002; Liégeois et al., 2003). Misconceptions arise from prior experiences and misinterpretations of information at hand (Tsai, 2001; Sungur, Tekkaya \& Geban, 2001), resulting in naive understandings that are inconsistent with the scientific view (Duit, 2002). In general, misconceptions are resistant to change (Ronen \& Eliahu, 2000). Changing students' concepts is not simply the adding of new information, but is a process that enables students to synthesise models in their own minds, beginning with their existing explanatory frameworks (Vosniadou, 2002). According to Chi and Roscoe (2002), conceptual change is repair of misconceptions. Starting with naive conceptions, the instruction must help students to identify their faulty conceptions and repair them. In this view, misconceptions are miscategorisations of concepts, so conceptual change is the reassignment of concepts to correct categories. Thus, physics instructors need to search for a new philosophy in which learners are actively constructing their own knowledge (Jong et al., 1998), and instructors recognise students' previous difficulties (Cataloglu, 2006). These are the key concepts of constructivism where students' are encouraged to construct their own knowledge based on their existing knowledge and through an active participation.

\section{Studies on direct current electricity}

The abstract nature of concepts in electricity leads students to develop many misconceptions related to concepts of current, potential difference, complete circuit, and power dissipated within a circuit element. These misconceptions have been the focus of many studies in physics education (e.g., McDermott \& Shaffer, 1992a; Lee \& Law, 2001; Engelhardt \& Beichner, 2004; Sencar \& Eryilmaz, 2004; Periago \& Bohigas, 2005), are common to both students and teachers, and are observed in various countries (Shipstone et al., 1998).

Many young students considered that a single wire is enough to carry current from the positive terminal of the battery to a bulb (sink model, Fredette \& Lochhead, 1998). Alternatively, some students think that currents coming from positive and negative terminal meet at the bulb, are used up in the bulb and shine it (clashing current, Osborne, 1983). Many students thought that current flows in one direction around the circuit and is being used up so less is available to other elements further along in the circuit (sequence model, Shipstone et al, 1984; attenuation model, Osborne, 1983). When students are asked to deduce potential difference from resistance and current information, most of them relied only on current, and ignored or underestimated the importance of resistance information (Liégeois \& Mullet, 2002; Liégeois et al., 2003). This caused another misconception that, in an open circuit, there is no potential difference (Engelhardt \& Beichner, 2004). Students also have many difficulties in 
analysing electric circuits. For example, if a circuit is modified, they tend to analyse only the modified part of the circuit (localist approach) rather than the whole circuit (Cohen, Eylon \& Ganiel, 1983). Students also have difficulty with electric diagrams and short circuit. A complete list of students' difficulties and misconceptions related to direct current electricity is provided by Engelhardt and Beichner (2004).

Studies showed that traditional electricity courses does not much alter students' misconceptions (e.g., Jaakkola, Nurmi \& Lehtinen, 2005; Jaakkola \& Nurmi, 2004; Liégeois \& Mullet, 2002). Evans (1978) suggested a teaching strategy which enforces qualitative understanding of electric circuits. Evans used batteries and bulbs as teaching material. Upcoming researchers used Evans' teaching strategies that utilise batteries and bulbs as teaching materials, to foster understanding of concepts related to simple electric circuits (e.g., Engelhardt, Gray \& Rebello, 2004; Slater, Adams \& Brown, 2000; McDermott \& Shaffer, 1992b). For example, Ates (2005) applied a teaching strategy based on a learning cycle method that included batteries and bulbs. He found that providing constructivist teaching with batteries and bulbs used as primary teaching materials was effective in increasing students' understanding of simple electric circuits. Other methods that take students' misconceptions into account seems to be effective for changing misconceptions related to the electric circuits. For example, Wang and Andre (1991) demonstrated that texts developed for facilitating conceptual change improved acquisition of qualitative concepts about simple electrical circuits. Laboratory based activities improve students' conceptual understanding of current electricity (McDermott \& Shaffer, 1992b). On the other hand, some deep misconceptions may not be altered by direct experience with the real electric circuits (Ronen \& Eliahu, 2000).

\section{Computer simulations and active learning}

In general, traditional physics experiments aim at convincingly demonstrating concepts. This means that the result obtained from the experiment should agree sufficiently well with the predicted value to persuade the student that the concept is true. Owing to apparatus or method reasons, agreement is often not satisfactory. Thus, students are usually left questioning why there is such a discrepancy (Sethi, 2005). This may cause students to disbelieve the experiment that they carried out and the fostering of conceptual change fails. However, computer simulations provide exact agreement with the predicted outcomes, thus reinforcing students' understanding of relationships between variables.

Constructivist approaches emphasise active learning (Donaldson, 2005) which is described as "providing opportunities for students to meaningfully talk and listen, write, read, and reflect on the content, ideas, 
issues, and concerns of an academic subject" (Meyers \& Jones, 1993, p. 6). One way of creating an active learning environment is the use of "What if..." questions (IDS, 2002, p.8-1; Sokoloff \& Thornton, 1997). Computer simulations can be used to build such an environment. For example, Mzoughi et al. (2005) used WebTop with "what will happen if ..." kinds of questions, to provide an ideal mechanism for creating an active learning environment. Studies showed that computer simulations contribute to students' understanding of physics concepts. Dori et al. (2003) indicated that visualising abstract concepts in physics by simulations enhances students' conceptual understanding, and promotes active learning. Students in their study said that utilising computer simulations contributed to their conceptual understanding. Sethi (2005) explained how to set up virtual laboratories to enhance learning in physics. Papaevripidou, Hadjiagapiou and Constantinou (2005) used computer simulations to foster conceptual understanding in conservation of momentum. Lee, Nicol and Brooks (2004) indicated that Physlets (undated) are very useful for correcting student misconceptions. Physlets (Physics Applets) are small, flexible Java applets designed for science education. Jaakkola, Nurmi and Lehtinen (2005) used Electricity Exploration Tool to simulate electric circuits and showed that a computer simulation was able to improve students' understanding of current electricity compared to the laboratory work.

\section{Free open source software (FOSS) in physics education}

Thompson (2002, p.101) explained the importance of the use of FOSS in education in these terms:

...open source software will provide new and exciting possibilities for educators. Obviously, the free or low cost availability of open source software has great appeal for educators at all levels ... the opportunity provided by open source software for education to adapt software to the needs of their students. In the same way a teacher might adapt a lesson plan to his or her needs; open source software may provide the opportunity to adapt a software program.

Moelter (undated) from California Polytechnic State University uses free open source software, Vpython, simulations to discuss what to expect in advance of showing the result. VPython is used as a teaching material by Salgado (undated) at the Department of Physics, Syracuse University.

Sethi (2005) demonstrated that physics educators can utilise free open source software to set up virtual physics laboratories that contribute students' understanding of difficult physics subjects. Sanchez (2005) introduced Linux and other FOSS with special emphasis upon physics research and education. Cataloglu and Baser (2005) used FOSS to teach vectors to freshman physics students. They concluded that the software 
they used enhanced students' understanding of vectors. Another similar study was done by Cataloglu (2006). He found that students who utilised FOSS in their learning performed better than students who did not.

Most educational software that simulates electric circuits implements only predefined circuits (e.g. DC Circuits Challenge). These types of simulations fail to create active learning environments because students cannot alter the circuits. Instructors cannot ask "what happens if we modify the circuit..." kinds of questions to build an active learning environment.

Spice is a general purpose FOSS circuit simulation program for nonlinear DC, nonlinear transient, and linear AC analyses. The use of spice in electric circuit lessons is suggested by Kuphaldt (2006) in his Lessons in Electric Circuits which is a series of free textbooks on the subjects of electricity and electronics. Using spice is not easy because it requires the writing of a 'netlist' which describes a circuit. This non-visual property of spice inhibits its use in elementary physics courses. Qucs is an integrated circuit simulator having a graphical user interface (GUI) for circuit setup, to simulate the large-signal, small-signal and noise behavior of the circuit. After that simulation has finished one can view the simulation results on a presentation page or window. As setting up a circuit in Qucs is very easy, it is possible to use it with little difficulty in first year physics courses to simulate circuits. GEDA is another FOSS visual circuit simulator that can be used instead of Qucs. One can use similar commercial circuit simulators to build active learning environments and promote conceptual change. For example, Pspice and CircuitMaker are other commercial circuit simulators very similar to Qucs. However, this study concentrates upon free open source software to promote conceptual understanding, and thus Qucs was chosen as the circuit simulator instead of a commercial equivalent.

\section{Method}

Purpose

The first purpose for this study is to investigate the building of an active learning environment utilising Qucs FOSS for simple DC circuit simulations. The second purpose is to test the immediate and delayed contribution of Qucs simulations to students' understanding of DC circuits.

Subjects and setting

The students participating in this study were pre-service elementary mathematics teacher students, enrolled in two classes of a science education course at Abant Izzet Baysal University $(n=102$, male=59, female $=43$ ). As a minor area for elementary mathematics teachers is science education, they had previously studied General Physics II, a calculus based course that includes the topics of static electricity, direct current circuits 
and magnetism. The students ranged in age from 21-24 years and their native language and language of instruction was Turkish. Students worked individually on computers.

\section{Experimental design and instruments}

To explore the effectiveness of Qucs simulations on developing students' understanding, the direct current electricity test (DCET) was administered to all students at the beginning of the instruction, immediately after instruction and six weeks after instruction. The questions in the DCET were multiple choice items with five alternatives, selected from version 1.2 of DIRECT developed by Engelhardt and Beichner (2004). Since it would not be possible to teach all the concepts assessed by DIRECT with QucS simulations, the objectives listed in Table 1 were selected. DCET consisted of 16 questions from DIRECT, selected according to the objectives in Table 1. The test was translated and adapted to Turkish by the author. The translated version of DIRECT was examined and verified by two physics instructors experienced in English. Prior to this study, the test was applied to a total of 243 elementary school, elementary science, and mathematics pre-service teachers. The range, mean, standard deviation and reliability (KR20) of the Turkish version were 6-25, 14.90, 4.61 and 0.71 respectively.

Table 1: Objectives for DCET and number of questions assessing each objective

\begin{tabular}{|l|c|}
\hline \multicolumn{1}{|c|}{ Objective } & $\begin{array}{c}\text { Number of } \\
\text { questions }\end{array}$ \\
\hline O1. To Identify and explain a short circuit & 3 \\
\hline O2. To understand open circuit & 2 \\
\hline $\begin{array}{l}\text { O3. To understand and apply conservation of current to simple direct } \\
\text { current circuits }\end{array}$ & 2 \\
\hline $\begin{array}{l}\text { O4. To understand and apply that the amount of current is influenced } \\
\text { by the potential difference provided by the battery and resistance in } \\
\text { the circuit. }\end{array}$ & 3 \\
\hline O5. To apply the concept of potential difference to circuits. & 5 \\
\hline O4 and O5 combined & 1 \\
\hline
\end{tabular}

All the tests were web based and served by a Python script written by author. At the end of the treatment, students were given an evaluation questionnaire containing 11 Likert type items. The purpose for this evaluation was to obtain students' perceptions of using Qucs in learning physics.

The activity sequence

Since the students had studied an electricity course (General Physics II) one year before this investigation, principles of direct current electricity were discussed with students for two hours in case they had forgotten the principles included in current electricity. In this short lecture, the following 
topics were summarised: potential difference, current, resistance, parallel and series combinations of resistors and batteries, measurement of current and potential difference, Ohm's and Kirchhoff's rules, and power dissipation in a circuit element. Some numerical problems were also solved. After this short introduction, students were administered DCET as a pre-test. After the pre-test, students in two classes were randomly divided into four groups, nearly 26 students in each group (a total of four groups). Students from each group were brought to a computer laboratory having 26 computers where each worked individually.

The students spent six hours in two sessions, each lasting three hours (one session per week) in the computer laboratory to fulfill the tasks. There were 19 simulation tasks that covered topics identified by objectives in Table 1. For some of the circuit simulations, experiments from Physics by Inquiry (McDermott et al., 1996) were used.

In the first hour of the first computer session, students were introduced to the Linux operating system and some of the educational software in KDE$E d u$, high quality FOSS educational software collection for the K Desktop Environment. For example, since these students will become mathematics teachers, they were advised about using KmPlot, a mathematical function plotter for the $K D E$. The possibility of using some other software such as KTurtle in their teaching careers had also been demonstrated. Although the participants had not used Linux OS previously, it was noticed that their motivation toward Linux OS and KDE software was very high.

Simulation tasks were assigned by the researcher. The researcher tried to ensure that collaborative learning did not take place while students performed the given task. After the students finished each task individually, a whole class discussion was conducted to provide an opportunity for them to reflect on their findings.

The next step was to introduce Qucs to students. An extensive Turkish tutorial on using Qucs for beginners was prepared by the author. Students used this tutorial as supplementary material throughout their study with Qucs (in Turkish, at http://mbaser.web.ibu.edu.tr/Qucs/, translation by the author). As an introduction, students set up a simple circuit containing a battery, a resistor and an ammeter as shown in Figure 1. Figures give screenshots for an English reader although the students used the Turkish version of Qucs.

After the first circuit with which students learned using Qucs to simulate electric circuits, students asked "what happens ... if I ..." questions to build an active learning environment as Sokoloff and Thornton (1997) suggested. The first question was "What happens to the current read by the ammeter 


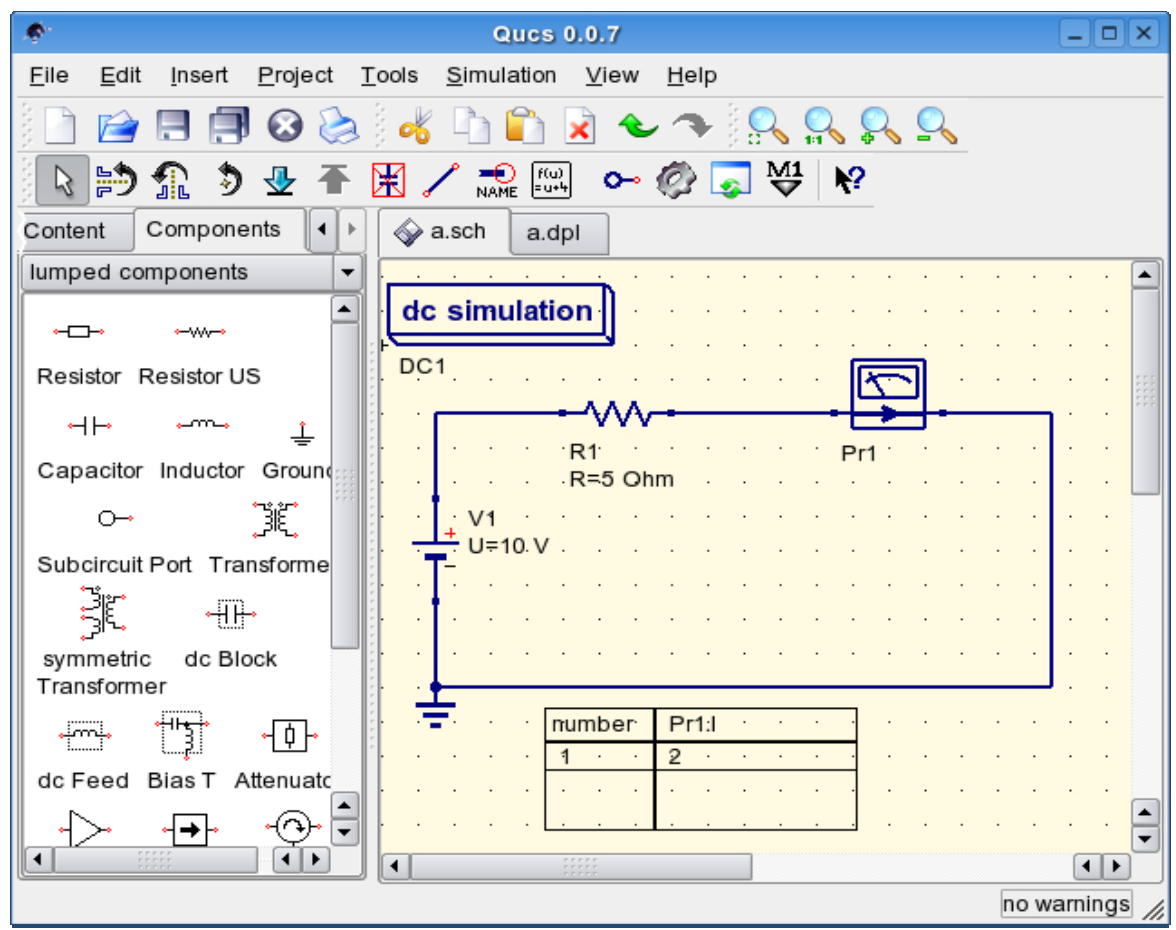

Figure 1: A simple circuit simulation with Qucs

if I add an equivalent resistor in series to the first resistor?" Students set up the circuit and observed the change in the current probed by the ammeter. Students were asked to infer the change in power dissipation in the first resistor after modification. Then students were asked to add another series resistor to the circuit. Some of the questions for were:

- What will happen to current passing through R2 if I short circuit R1?

- What will happen to the power delivered to circuit by the battery if I open the branch connecting R3?

- What will happen to the potential difference across resistor R2 if I add another equivalent battery in series to the first battery?

- What will happen to the potential difference across resistor R2 if I add another equivalent battery in parallel to the first battery?

As an example students first set up the circuit shown in Figure 2 where all circuit components are identical. In this circuit two parallel resistors are connected in series to another resistor. When students were asked to explain the change in current through R1 when R2 is short circuited, most 
tended to analyse locally. That is, they considered only changes through R3 and responded that current through $\mathrm{R} 1$ remains the same. When students simulated the change, they saw that current through R1 changes as well as through R3. These types of activities provide a means for attaining an active learning environment and promoting conceptual understanding.

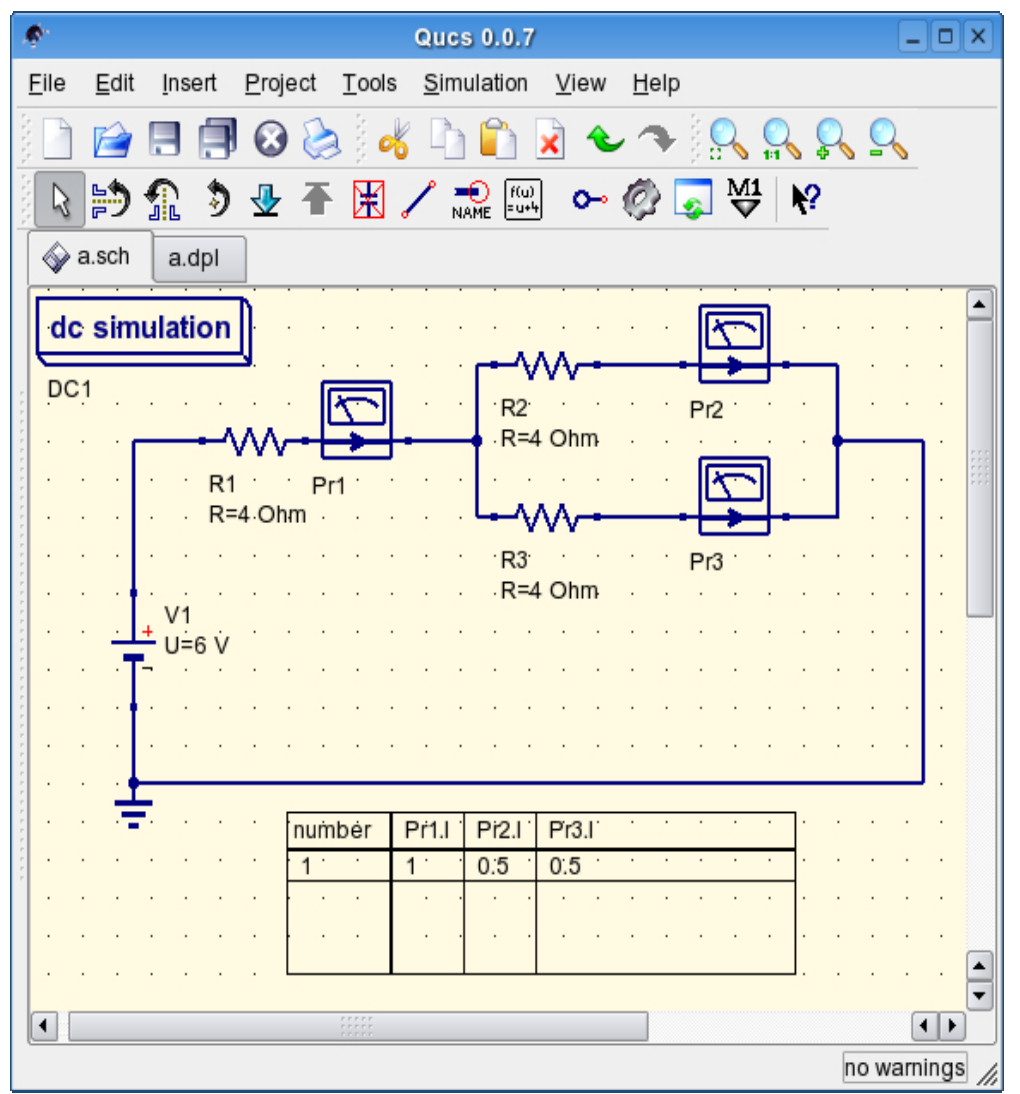

Figure 2: Two parallel resistors connected in series to a third resistor

There was no voltmeter object in Qucs to measure potential difference across a circuit element when this study was made. Instead, Qucs can measure potential on a point with respect to ground. It was speechless for students when they first encountered "potential on a point". But subsequent information provided for them makes the concept of potential on a point clear. This relied on an analogy for potential drop, as depicted in Figure 3. 


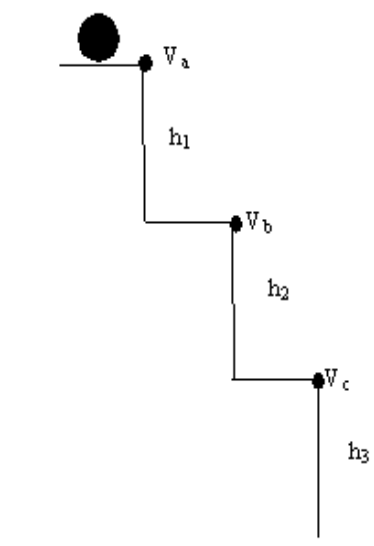

Drop in Potential Energy of Ball

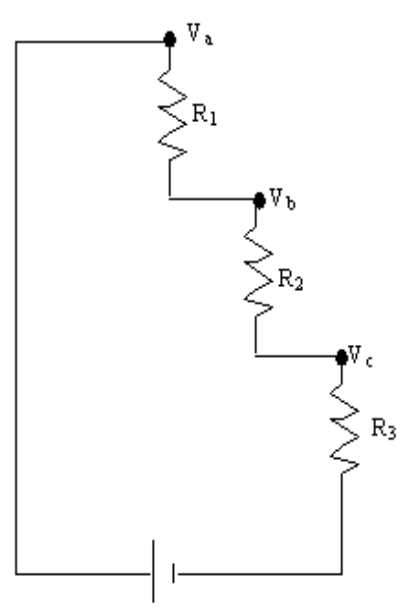

Drop in Potertial in a Circuit

Figure 3. Ladder analogy for potential drop in electric circuits

This analogy enables students to understand "potential drop" as well as the cause of current in a circuit element. After this analogy and measuring potential drop in circuits, many participants in this study made statements such as "Before this analogy I always thought that the cause of potential difference across a circuit element is the current flowing through it. But now I can safely say that, the current through a circuit element is due to the potential difference across it."

After two sessions totalling 6 hours were completed, the DCET was administered as a post-test. The evaluation questionnaire was given also.

\section{Results}

Development of students understanding in direct current electricity

To evaluate the effectiveness of Qucs simulations, all students were administered DCET before the treatment and after the treatment. A six week delayed post-test also was administered to assess whether the change in achievement was durable. The data was analysed by using Rweb, a web interface for $R$, a free software environment for statistical computing and graphics. Paired t-test was used to evaluate students' progress in understanding of direct current electricity concepts as measured by DCET. The analysis of data for comparison of pre and post DCET scores is shown in Table 2. 
Table 2: Measures obtained from testing of significance of the difference between pre- and post-means of direct current electricity test (DCET)

\begin{tabular}{|l|c|c|c|c|c|c|}
\hline Tests & $\mathrm{n}$ & mean & $\mathrm{s}$ & $\mathrm{df}$ & $\mathrm{t}$-value & $\mathrm{p}$ \\
\hline Pre DECT & \multirow{2}{*}{102} & 7.25 & 2.22 & 101 & 16.33 & $0.00^{*}$ \\
\cline { 1 - 5 } Post DECT & & 10.55 & 2.08 & & & \\
\hline \multirow{2}{*}{$\mathrm{p} p<0.05$} &
\end{tabular}
${ }^{*} \mathrm{p}<0.05$

The results showed that there was a significant difference between the pre and post-test mean scores of the students who received active learning instruction with Qucs simulations (Figure 4). It can be concluded that posttest scores were significantly improved: the average percent of correct responses increased from $45.3 \%$ to $65.9 \%$, resulting in average normalised gain, $\langle\mathrm{g}>=0.38$. The overall average normalised gain (see Appendix for a description) for students in this study was in the "medium" category as defined by Hake (1998). Gains for individual objectives (Table 3) showed least improvement for objective 4 and paired $t$-test analyses revealed that it was not significant.

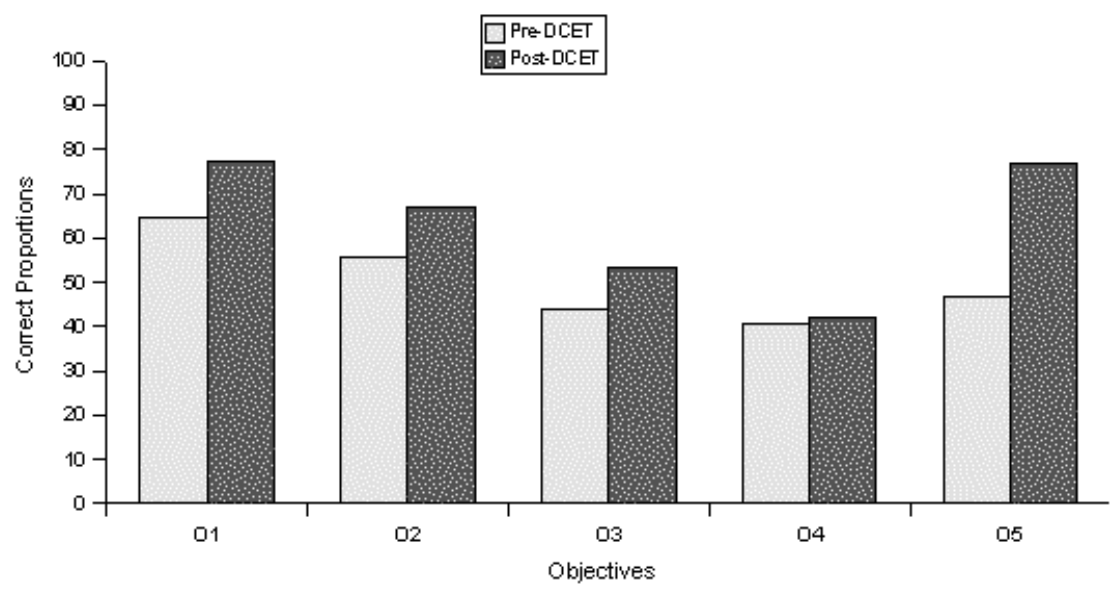

Figure 4: Proportions of correct responses in pre-DCET and post-DCET by objective as listed in Table 1

Table 3: Average normalised gain by objective on DECT

\begin{tabular}{|c|c|c|}
\hline Objective & $<\mathrm{g}>$ & Category \\
\hline O1 & 0.4 & Medium \\
\hline O2 & 0.3 & Medium \\
\hline O3 & 0.2 & Low \\
\hline O4 & 0.1 & Low \\
\hline O5 & 0.6 & Medium \\
\hline
\end{tabular}


The questions for assessing objective 4 were related to power dissipation in circuits. For example, in one question, where all circuit elements are identical, a bulb is connected to a battery in the first circuit. In the second circuit, two bulbs in series were connected to a battery. Students were asked to compare the brightness of the bulbs. More than $90 \%$ of the students selected an incorrect answer for this question. This indicated that students still thought that the brightness of a bulb was directly related to the current passing through it (I) rather than power consumed in the bulb $\left(I^{2} R\right)$. Thus, it can be concluded that the instruction based on Qucs simulations failed to change misconceptions related to power consumption in a circuit. As this result was unexpected, seven students who had given incorrect answers to this question were interviewed. Students were asked to express their reasoning; and all confirmed their incorrect conception of a direct relationship between the current and the brightness of a bulb.

The greatest gain was obtained with objective 5 . The questions for objective 5 were related to comparisons of potential differences between two points when a circuit is modified or in an open circuit. For example, in one question, students were asked about a potential difference across two points where a current does not exist. In the pretest, $84.3 \%$ of the students selected zero potential. When students were asked to reveal their reasoning, they stated that "Potential difference equals current times resistance. Since there is no current, potential difference is zero". This way of thinking is consistent with the results obtained by Liégeois et al. (2003). Almost all students (95.1\%) answered this question correctly in the post test. The treatment seemed to be successful in changing this misconception.

Table 4: Measures obtained from testing of significance of the difference between post and delayed post means of direct current electricity test (DCET)

\begin{tabular}{|l|c|c|c|c|c|c|}
\hline \multicolumn{1}{|c|}{ Tests } & $\mathrm{n}$ & mean & $\mathrm{s}$ & $\mathrm{df}$ & $\mathrm{t}$-value & $\mathrm{p}$ \\
\hline Post DECT & 102 & 10.55 & 2.08 & 101 & 1.77 & 0.80 \\
\cline { 1 - 1 } Delayed post DECT & & 10.41 & 1.82 & & & \\
\hline
\end{tabular}

Paired $t$-test results for post and delayed post scores for DCET are shown in Table 4. Analyses of data revealed no significant difference between post and delayed post DCET scores. This result suggests that students' improved understanding of electric circuits was durable. The mean of the retention DCET was 10.41 and average percent of correct responses was $65 \%$. It can be said that changes in conceptual understanding of direct current circuits by Qucs simulations were retained at least in the short term. 
Students' evaluation of treatment and Qucs

Students were administrated an evaluation questionnaire having 11 Likert type items, after the treatment. Students selected one of the alternatives: fully agree (5), agree (4), undecided (3), not agree (2), fully disagree (1). The results are shown in Table 5.

Table 5: Students evaluations of treatment and Qucs

\begin{tabular}{|c|l|c|}
\hline \multicolumn{1}{|c|}{ Item } & $\begin{array}{c}\text { Average } \\
\text { score } \\
\text { (out of 5) }\end{array}$ \\
\hline 1 & $\begin{array}{l}\text { The contribution of computer simulations to my understanding of } \\
\text { electric circuits is comparable that of real laboratory experiments. }\end{array}$ & 4.54 \\
\hline 2 & $\begin{array}{l}\text { Computer simulations contributed to my understanding of electric } \\
\text { circuits. }\end{array}$ & 4.58 \\
\hline 3 & Topic of electricity become fun with computer simulations. & 4.70 \\
\hline 4 & $\begin{array}{l}\text { I would better understand other subjects of physics if I had chance } \\
\text { to use computer simulations. }\end{array}$ & 4.48 \\
\hline 5 & It is easy to make electric simulations with Qucs. & 4.19 \\
\hline 6 & The software we used is sufficient for electric circuit simulations. & 3.98 \\
\hline 7 & $\begin{array}{l}\text { The software we used matches the objectives of the General } \\
\text { Physics II course. }\end{array}$ & 4.48 \\
\hline 8 & $\begin{array}{l}\text { I suggest these simulations for other students who learn electric } \\
\text { circuits. }\end{array}$ & 4.66 \\
\hline 9 & \begin{tabular}{l} 
I enjoy making simulations of electric circuits with Qucs. \\
\hline 10
\end{tabular} & $\begin{array}{l}\text { I enjoy setting up circuits that I want. } \\
\text { Using open source free software in teaching may contribute } \\
\text { learning. }\end{array}$ \\
\hline
\end{tabular}

As Table-5 indicates, students' perceptions are positive toward computer simulations and Qucs. All students did simple electric circuit experiments during their General Physis II course one year before this study. High scores on item 1 indicated that students almost fully agreed that Qucs simulations contributed to their understanding of electric circuits, compared with real laboratory experiments. Although the average score for item 6 was quite high, students had some suggestions. For example, some wondered why they could not measure potential difference rather than measuring potential at a point (actually they are measuring potential difference between a point and the ground). This suggestion was quoted to the developers of Qucs and they intend to implement a 'voltmeter object' in the next version.

Qucs has facilities for users to save, retrieve and share a circuit simulation. As students seemed to like these features, the researchers asked whether they preferred to use saved circuit simulations or set up their own circuits. Only $17 \%$ of the students indicated that they preferred to use saved circuit simulations. This preference could be the subject for further research. 


\section{Conclusions}

The purpose for this study was to show the possibility of building an active learning environment by the use of free open source software, Qucs, and to evaluate its effectiveness upon students' understanding of direct current electric circuits. The researcher feels that Qucs is a tool for improving students' conceptual frameworks. It gives an opportunity for instructors to understand students' thinking and to foster conceptual change. The analysis of data indicated that students' progress in understanding direct current electric circuits was significant and was retained after six weeks. Furthermore, students' perceptions of the exercise and the software were very positive.

Using Qucs simulations, students were asked "what will happen if ..." kinds of questions to create an active learning environment, as Sokoloff and Thornton (1997) proposed. Students also were asked to analyse certain electric circuits, to produce numerical or qualitative answers to questions, and then to use Qucs to simulate the circuit and check their answers. Furthermore, the data obtained from Qucs simulations is exactly what is predicted, to convince the students that a concept is true (Sethi, 2005). These activities fostered conceptual change.

Computer simulations should not make the experiment more difficult, either conceptually or procedurally, but should rather provide clear explanations and encourage understanding (Redish \& Risley, 1990). According to students' evaluation, one may conclude that it is easy to make cicuit simulations with Qucs.

Traditional methods teaching of electric circuits depend highly on the mathematical applications of Ohm's law, without going deeper into a qualitative analysis of it from the point of view of physics. Simulation exercises can be used (Periago \& Bohigas, 2005) to cope with this problem. This study used computer simulations to encourage qualitative reasoning and showed that the activities promoted students' conceptual understanding of direct current electricity.

The success of computer simulations in changing student's conceptual understanding of direct current electric circuits does not indicate any possibility for completely replacing traditional laboratory experiments (Forinash \& Wisman, 2005). The topic of electricity is so complex that development of understanding of simple circuits requires direct experiences and hands on activity with the real electric circuits (Shipstone et al., 1988). However, effective combinations of real laboratory experiments with Qucs simulations should be checked as Jaakkola, Nurmi and Lehtinen (2005) did for Electricity Exploration Tool. 
The result of this study provided evidence that free open source software, Qucs in this case, can be used successfully in physics teaching. Qucs can also be used to check the solution of chapter end problems from a textbook. Other possible uses may be in class demonstrations when teaching series and parallel connections of resistors.

\section{References}

Ates, S. (2005). The effectiveness of the learning-cycle method on teaching DC circuits to prospective female and male science teachers. Research in Science $\mathcal{E}$ Technological Education, 23(2), 213-227.

Baser, M. (2003). Effect of instruction based on conceptual change activities on students' understanding of electrostatics concepts. Unpublished PhD dissertation, METU, Ankara.

Cataloglu, E. (2006). Open source software in teaching physics: A case study on vector algebra and visual representations. The Turkish Online Journal of Educational Technology, 5(1), Article 8. http:/ / www.tojet.net/articles/518.htm

Cataloglu, E. \& Baser, M. (2005). Open source software in teaching physics: A case study on vector algebra and visual representations. Open Source for Education in Europe, Research $\mathcal{E}$ Practice - Conference proceedings. Open University of the Netherlands. Heerlen, 2005. http:/ / www.openconference.net/viewpaper.php?id=28\&cf=3

Chi, M. T. H., \& Roscoe, R. D. (2002). The process and challenges of conceptual change. In M. Limon \& L. Mason (Eds), Reconsidering conceptual change: Issues in theory and practice (pp. 3-27). Dordrecht: Kluwer.

CircuitMaker (undated). CircuitMaker - the virtual electronics lab. http:/ / www.microcode.com/ [verified 24 July 2006]

Cohen, R., Eylon, B. \& Ganiel U. (1983). Potential difference and current in simple electric circuits: A study of student's concepts. American Journal of Physics, 51(5), 407-412.

DC Circuits Challenge (undated). Training software for DC electrical circuits. http:/ / www.etcai.com/page3.html [verified 24 July 2006]

Donaldson, N. (2005). Addressing misconceptions in a constructivist, applicationbased physics course. Paper presented at The Thirty-Fifth Annual Conference of the International Society for Exploring Teaching and Learning (ISETL), 13-15 October, Cocoa Beach, Florida. [verified 24 July 2006] http:/ / www.isetl.org/conference/presentation.cfm?pid=215

Dori, Y. J., Belcher, J., Bessette, M., Danziger, M., McKinney, A. \& Hult E. (2003). Teaching for active learning. Materials Today, December 2003, p 44-49.

Duit, R. (2002). Conceptual change - still a powerful frame for improving science teaching and learning? Paper presented at the Third European Symposium on Conceptual Change, 26-28 June, Turku, Finland. [verified 24 July 2006; $2.3 \mathrm{MB}$ ] http://www.edu.utu.fi/konf/Proceedings.pdf 
Electricity Exploration Tool (undated). NLN learning materials. [verified 24 July 2006] http:/ / nln.mimas.ac.uk/

Engelhardt, P. \& Beichner, R. (2004). Students understanding of direct current resistive electrical forces. American Journal of Physics, 72(1), 98-115.

Engelhardt, P. V., Gray K. E. \& Rebello, N. S. (2004). How many students does it take before we see the light? The Physics Teacher, 42(4), 216-221.

Eryilmaz, A. (2002). Effects of conceptual assignments and conceptual change discussions on students' misconceptions and achievement regarding force and motion. Journal of Research in Science Teaching, 39, 1001-1015.

Evans, J. 1978. Teaching electricity with batteries and bulbs. The Physics Teacher, 16(1), 15-22.

Forinash K. \& Wisman, R. (2005). Building real laboratories on the internet. International Journal of Continuing Engineering Education and Lifelong Learning, 15(1/2), 56-66.

Fredette, N. \& Lochhead, J. (1980). Student conceptions of simple circuits. Physics Teacher, 18(3), 194-198.

GEDA (undated). gEDA project homepage. http://www.geda.seul.org/

Gnuplot (undated). gnuplot homepage. http:/ /www.gnuplot.info/

Hake, R. (1998). Interactive engagement versus traditional methods: A six-thousand student survey of mechanics test data for introductory physics courses. American Journal of Physics, 66(1), 64-74

IDS (2002). Instruction at FSU: A guide to teaching and learning practices. 4th ed. Instructional Development Services, Florida State University. http:// online.fsu.edu/learningresources/handbook/instructionatfsu/PDFCover-TOC.pdf [verified 24 July 2006]

Jaakkola, T. \& Nurmi, S. (2004). Academic impact of learning objectives: The case of electric circuits. Paper presented at Learning objects in the classroom: A European perspective, symposium at the British Educational Research Association annual conference, Manchester, 16-18 September.

Jaakkola, T., Nurmi, S. \& Lehtinen, E. (2005). In quest of understanding electricity Binding simulation and laboratory work together. Paper for AERA (American Educational Research Association) 2005 conference. Montreal, Canada, 11-15 April.

Kuphaldt, T. R. (2006). Lessons In Electric Circuits. http://www.ibiblio.org/obp/electricCircuits/

KDE-Edu (undated). The KDE Edutainment Project. http:/ / edu.kde.org/

LaTeX (undated). LaTeX project: LaTeX - A document preparation system. http://www.latex-project.org/

Lee, K. M., Nicoll, G. \& Brooks, D. W. (2004). A comparison of inquiry and worked example web-based instruction using physlets. Journal of Science and Technology, 13(1), 81-88. 
Lee, Y. \& Law, N. (2001). Explorations in promoting conceptual change in electrical concepts via ontological category shift. International Journal of Science Education, 23(2), 111-149.

Liégeois, L. \& Mullet, E. (2002). High school students' understanding of resistance in simple series electric circuits. International Journal of Science Education, 24(6), 551-564.

Liégeois, L., Chasseigne, G., Papin, S. \& Mullet, E. (2003). Improving high school students' understanding of potential difference in simple electric circuits. International Journal of Science Education, 25(9), 1129-1145.

McDermoot, L.C. et. al. (1996). Physics by Inquiry, Volume II. John Wiley \& Sons, Inc., New York.

McDermott, L.C. \& P.S. Shaffer (1992a). Research as a guide for curriculum development: An example from introductory electricity. Part I: Investigation of student understanding. American Journal of Physics, 60(11), 994-1003.

McDermott, L.C. \& P.S. Shaffer (1992b). Research as a guide for curriculum development: An example from introductory electricity. Part II: Design of instructional strategies. American Journal of Physics, 60(11), 1003-1013.

Meyers, C. \& Jones, T. B. (1993). Promoting active learning: Strategies for the college classroom. San Francisco: Jossey-Bass.

Moelter, M. (undated). VPython in Physics. [verified 24 July 2006] http://www.calpoly.edu/ mmoelter/Python/VPython.html

Mzoughi T., Foley J. T., Herring S. D., Morris M. \& Wyser B. (2005). WebTOP: Webbased interactive 3D optics and waves' simulations. Journal of Continuing Engineering Education and Life-Long Learning, 15(1/2), 79-94

Novak, J. D. (2002). Meaningful learning: The essential factor for conceptual change in limited or inappropriate propositional hierarchies leading to empowerment of learners. Science Education, 86, 548-571.

Octave (undated). Octave homepage. http://www.gnu.org/software/octave/

Osborne, R. (1983) Towards modifying children's ideas about electric current. Research in Science and Technology Education, 1(1), 73-82.

Papaevripidou, M., Hadjiagapiou, M. \& Constantinou, C. P. (2005). Combined development of middle school student's conceptual understanding of momentum conservation, procedural skills and epistemological awareness in a constructionist learning environment. International Journal of Continuing Engineering Education and Life-Long Learning, 15(1/2), 95-107.

Periago, M. C. \& Bohigas, X. (2005). A study of second-year engineering students' alternative conceptions about electric potential, current intensity and Ohm's law. European Journal of Engineering Education, 30(1), 71-80.

Physlets (undated). Physlets resource page. http:/ / webphysics.davidson.edu/Applets / Applets.html 
Piquette, J. S. \& Heikkinen, H. W. (2005). Strategies reported used by instructors to address student alternate conceptions in chemical equilibrium. Journal of Research in Science Teaching, 42(10), 1112-1134.

Pspice (undated). Pspice download page. Electronics Lab. http:/ / www.electronicslab.com/downloads/schematic/ [verified 24 July 2006]

PXES (undated). PXES homepage. 2X Software Ltd. http:/ /www.2x.com/pxes/

Qucs (undated). Qucs project. http://qucs.sourceforge.net/

R (undated). The R Project for Statistical Computing. http:/ / www.r-project.org/

Redish, E.F. \& Risley, J.S. (Eds) (1990). The Conference on Computers in Physics Instruction Proceedings. Addison-Wesley Publishing, Redwood City, CA.

Ronen, M. \& Eliahu, M. (2000). Simulation - A bridge between theory and reality: The case of electric ciruits. Journal of Computer Assisted Learning, 16, 14-26.

Rweb (undated). Rweb homepage. http:/ / bayes.math.montana.edu/Rweb/

Salgado, R. (2006). VPython applications for Teaching Physics. [verified 24 July 2006] http://www.physics.syr.edu/ salgado/software/vpython/

Sanchez, A. L. C (2005). Doing physics with free/open-source software. Paper presented at 7th National Physics Conference and Workshop, Mindano State University, 27-29 October. [verified 24 July 2006] http:/ / physics.msuiit.edu.ph/spvm/papers/2005/sanchez.pdf

Savinainen, A., Scott, P. \& Viiri, J. (2005). Using a bridging representation and social interactions to foster conceptual change: Designing and evaluating an instructional sequence for Newton's Third Law. Science Education, 89(2), 175-195.

Sencar, S. \& Eryilmaz, A. (2004). Factors mediating the effect of gender on ninthgrade Turkish students' misconceptions concerning electric circuits. Journal of Research in Science Teaching, 41(6), 603-616.

Sethi, R. J. (2005). Using virtual laboratories and online instruction to enhance physics education. Journal of Physics Teacher Education Online, 2(3), 22-26. http://www.phy.ilstu.edu/jpteo/issues/jpteo2(3)feb05.pdf

Shipstone, D. M., von Rhöneck, C., Jung, W., Kärrqvist, C., Dupin, J. J., Joshua, S. \& Licht, P. (1988). A study of students' understanding of electricity in five European countries. International Journal of Science Education, 10(3), 303-316.

Shipstone, D. M. (1984). A study of children's understanding of electricity in simple DC circuits. European Journal of Science Education, 6(2), 185-198.

Slater, T. F., Adams, J. P. \& Brown, T. R.(2000). Completing a simple circuit. Journal of College Science Teaching, 30(2), 96-99.

Sokoloff, D. R. \& Thornton, R. K. (1997). Using interactive lecture demonstrations to create an active learning environment. The Physics Teacher, 35(6), 340. 
Spice (undated). The Spice Page.

http:/ /bwrc.eecs.berkeley.edu/Classes/IcBook/SPICE/

Sungur, S., Tekkaya, C. \& Geban, O. (2001). The contribution of conceptual change texts accompanied by concept mapping to students' understanding of the human circulatory system. School Science and Mathematics, 101(2), 91-101.

Thompson, A. (2002). The open source software movement: Implications for teacher educators. Journal of Computing in Teacher Education, 18(4), 110.

Tsai, C. (2001). Collaboratively developing instructional activities of conceptual change through the Internet: Science teachers' perspectives. British Journal of Educational Technology, 32(5), 619-622.

Vosniadou, S. (2002). On the nature of naive physics. In M. Limon \& L. Mason (Eds), Reconsidering conceptual change: Issues in theory and practice. (pp. 61-76). Dordrecht: Kluwer.

Vpython (undated). 3D Programming for Ordinary Mortals. http://www.vpython.org/

Wang, T. and Andre T. (1991). Conceptual change text versus traditional text and application questions versus no questions in learning about electricity. Contemporary Educational Psychology, 16(2), 103-116.

\section{Appendix: Average normalised gain}

Average normalised gain is a useful method to assess the effectiveness of instruction. Average normalised gain, $\langle g\rangle$, is defined as the ratio of the average improvement in participant scores from pre-test to post-test with respect to the maximum possible improvement. $\langle\mathrm{g}\rangle$ can be calculated:

$$
<\mathrm{g}>=\frac{\mathrm{X}_{\text {post }}-\mathrm{X}_{\text {pre }}}{100-\mathrm{X}_{\text {pre }}}
$$

Hake (1998) argues that the normalised gain is a meaningful measure of how well a course teaches topics in physics to students. Hake considered normalised gains in three categories: "high" for a normalised gain greater than 0.7 , "medium" between 0.3 and 0.7 , and "low" below 0.3. Traditional courses typically have low $<\mathrm{g}>$.

Dr Mustafa Baser, Department of Secondary Science and Mathematics

Education, Faculty of Education, Abant Izzet Baysal University, Golkoy

Kampusu, Bolu, Turkey. Web: http://www.ibu.edu.tr/en/

Email: mbaser@ibu.edu.tr 